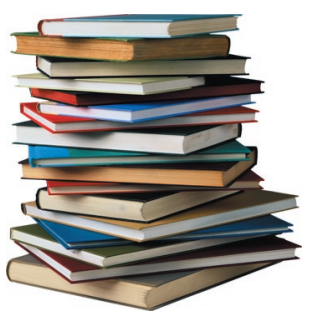

Коллектив научной медицинской библиотеки НИИ СП им. Н.В. Склифосовского предлагает читателям журнала обзор книг и методических материалов на русском языке, вышедших из печати в последние годы и освещающих как отдельные вопросы медицины критических состояний, так и различные аспекты медицинской науки в целом.

\section{ОРГАНИЗАЦИЯ ЗДРАВООХРАНЕНИЯ:}

1. O плагиате в диссертациях на соискание ученой степени: учеб. пособие / ВАК РФ. - 2-е изд., перераб. и доп. - М.: МИИ, 2015. - 192 с.

Во втором издании учебного пособия отражены основные нормативные и правовые акты, касающиеся рассматриваемого вопроса, включая порядок рассмотрения обращений по поводу недобросовестного заимствования. Представляя в настоящем обзоре данную книгу, непосредственно не связанную с какой-либо областью медицины, коллектив научной медицинской библиотеки НИИ СП им. Н.В. Склифосовского полагает, что современному специалисту вообще, а врачу в частности, насущно необходимо свободно ориентироваться во всем многообразии проблем, актуальных для современной науки в целом.

Многие ученые совершенно справедливо полагают, что плагиат - это вечный культурологический предмет обсуждения, но сегодняшние социально-экономические условия обострили отношение к нему, причем в основном из-за модной тенденции людей бизнеса и политики приобретать себе академические звания.

Для медицинского сообщества вопросы плагиата также являются необычайно острыми, причем не только для ученых, но и для практических врачей: клинический опыт одних иногда становится предметом недобросовестного использования другими.

\section{ХИРУРГИЯ:}

2. Хирургические болезни: учебник для вузов: в 2 т. / под ред. В.С. Савельева, А.И. Кириенко. - 2-е изд., перераб. и доп. - М.: ГЭОТАР-Медиа, 2014. т. 1. - 720 с.: ил.; Т. 2. - 688 с.: ил.

Второе, переработанное и дополненное издание учебника для программы высшего профессионального образования по специальности «Лечебное дело», написано ведущими специалистами страны - представителями всех ведущих хирургических школ. В нем в доступной форме с современных позиций изложены вопросы этиопатогенеза, диагностики и лечения наиболее часто встречающихся хирургических заболеваний.

Первый том состоит из двух частей, в первой из которых собраны сведения об общих принципах и методологии хирургии как науки, о методах обезболивания и обеспечения безопасности пациента при выполнении вмешательств, а во второй сообщаются подробные све-
«Учиться быть врачом - это значит учиться быть человеком»

А.Ф. Билибин дения об основных хирургчческих заболеваниях органов брюшной полости. Второй том состоит из четырех частей, каждая из которых посвящена технике и методике оперативного пособия при заболеваниях и травмах отдельных анатомических областей и систем.

Издание представляет большой интерес для всех врачей, и, в первую очередь, для занимающихся вопросами подготовки кадров.

3. Шабунин, А.В. Панкреонекроз. Диагностика и лечение / А.В. Шабунин, А.В. Араблинский, А.Ю. Лукин. - М.: ГЭОТАР-Медиа, 2014. - 96 с.: ил.

Богатый клинический опыт авторов - специалистов из нескольких научных и лечебных учреждений Москвы лег в основу монографии, сочетающей анализ мировой и отечественной литературы и собственных достижений и неудач. С позиций доказательной медицины сформулированы основные диагностические приемы и направления интенсивной терапии панкреонекроза, а также особенности хирургической тактики.

Приведенные в книге модели различных вариантов течения заболевания дают возможность практическому врачу осуществлять выбор оптимального доступа $к$ зонам поражения в поджелудочной железе и забрюшинной клетчатке. При этом авторами подчеркивается, что объемы диагностики и хирургической помощи могут варьироваться и выполняться с учетом существующих возможностей в каждом конкретном лечебном учреждении.

4. Эндоскопия. Базовый курс лекций: учеб. пособие / В.В. Хрячков, Ю.Н. Федосов, А.И. Давыдов [и др.]. - М.: ГЭОТАР-Медиа, 2014. - 153 с.: ил. - (Сер.: Библиотека врача-специалиста: Эндоскопия. Инструментальная диагностика).

Коллектив кафедры госпитальной хирургии ХантыМансийской ГМА на основе курса лекций создал монографию, в которой подробно и наглядно представил основные моменты, отражающие все особенности подготовки врача по специальности «Эндоскопия». После краткого исторического экскурса авторы большое внимание уделили организационным вопросам с подробной характеристикой современной эндоскопической аппаратуры $u$ инструментария, особенностями их обслуживания, в том числе дезинфекциии и стерилизации оборудования, а также техническим аспектам наиболее широко приме- 
няемых манипуляциий на различных органах с подробным описанием тактических приемов.

Среди оригинальных методик проведения эндоскопических исследований и вмешательств, разработанных авторами, несомненный интерес у врачей неотложной медицины вызовут главы, отражающие особенности проведения эндоскопии в ургентной медицине. Еще одним из несомненных достоинств монографии можно полагать глубокий анализ ошибок и осложнений при проведении эндоскопических вмешательств.

\section{АНЕСТЕЗИОЛОГИЯ И РЕАНИМАТОЛОГИЯ:}

5. Грин, Д. Геморрагические заболевания и синдромы / Д. Грин, К.А. Ладлем; пер. с англ. под ред. О.В. Сомоновой. - М.: Практическая медицина, 2014. - 131 с.: ил.

Второе издание справочника, являющегося, по мнению многих зарубежных и отечественных медиков, надежным источником информации о разных геморрагических состояниях, напрямую предназначено для специалистов различного уровня подготовки, непосредственно оказывающих помощь пострадавщим.

Текст, изложенный в удобной лаконичной форме, сопровождается наглядными иллюстрациями, облегчающими его восприятие. Поскольку большинство геморрагических состояний относятся к экстренным ситуациям, требующим незамедлительных мер по их купированию, справочник является именно тем пособием, к которому врач, фельдшер, медицинская сестра могут обращаться в сложных ситуациях для быстрого устранения кровотечений.

6. Шок: учеб-метод. пособие / В.В. Мороз [и др.]. - М.: НИИ Общей реаниматологии им. В.А. Неговского, 2014. - 31 с.

Пособие, разработанное с участием научных сотрудников НИИ общей реаниматологии им. В.А. Неговского и преподавателей кафедры анестезиологии-реаниматологии МГМСУ им. А.И. Евдокимова, дает лаконичное, но емкое представление обо всех видах шока, его патофизиологических аспектах, алгоритмах и принципах лечения каждого из них. Дана оценка эффективности применения современных лекарственных средств, направленных на купирование шоковых состояний, представлены основные принципы лечения и последовательность выполнения манипуляций.

\section{КАРДИОЛОГИЯ И КАРДИОХИРУРГИЯ:}

7. Лутра, А. ЭхоКГ понятным языком / А. Лутра; пер. с англ. под ред. Ю.А. Васюка. - 2-е изд. на рус. яз. - М.: Практическая медицина, 2014. - 129 с.: ил.

Второе издание на русском языке переведено с третьего англоязычного оригинала, увидевщего свет в 2012 году. Высокая практическая значимость в сочетании с лаконичностью и доступностью изложения делает его особенно привлекательным для специиалистов, занимающихся ультразвуковой диагностикой патологии сердечно-сосудистой системы.

У врачей, работающих в стационарах, оказывающих скорую помощь, наибольший интерес вызовут конкретные рекомендации по использованию ЭхоКГ в отделениях кардиохирургии и интенсивной терапии, а также подробные описания ультразвуковых особенностей различных заболеваний сердиа, изложенные с особым вниманием к возможным ошибкам в интерпретации получаемых изображений.
8. Митрев, Ж. Решения в сердечно-сосудистой хирургии / Ж. Митрев; пер. с франц. - М.: Изд-во ИТРК, 2014. - 240 с.: ил.

В основе богато иллюстрированной книги лежит обобщение клинической практики сердечно-сосудистого хирурга, выполнивщего свыше 15000 операций. По мнению коллег - автора предисловия и переводчика - она отражает современное состояние кардиохирургии в республике Македония, являясь уникальным примером практического решения сложных задач при заболеваниях сердиа и сосудов. Автор дает возможность познакомиться с возможностями хирургического лечения патологии сердечно-сосудистой системы, включая самые современные техники и методики - гибридные операции при комплексной патологии.

НЕВРОЛОГИЯ И НЕЙРОХИРУРГИЯ:

9. Вишневский, А.А. Спинной мозг / А.А. Вишневский, Н.В. Шулешова. - СПб., Фолиант, 2014. - 743 с.: ил.

Авторский коллектив монографии - физиологи, патофизиологи и нейрофизиологи, клинические фармакологи из нескольких медицинских центров СанктПетербурга, создали фундаментальный труд, отражающий многолетний опыт изучения проблем заболеваний и повреждений спинного мозга, который может стать полезным для самого широкого круга врачей: нейрохирургов, анестезиологов, травматологов, функциональных диагностов, терапевтов и врачей других специальносmей.

Монография с современных позиций дает развернутые ответы на целый ряд спорных вопросов, возникающих в процессе диагностики и лечения пациентов с заболеваниями и травматическими поражениями позвоночника и спинного мозга, в том числе подробно освещаются патофизиологические механизмы формирования спинального шока.

Несколько глав посвящены вертеброгенным синдромам и их диагностике (в том числе ликвородиагностике) патологических процессов, происходящих в спинном мозге, осложнениям и последствиям не только травм, но и проведения хирургических вмешательств на позвоночнике, а также поиску методов восстановления нарушенных функций спинного мозга.

10. Герсдорф, М. Хирургия среднего уха: атлас / С. Герсдорф, Ж.-М. Жерар; пер. с англ. под ред. В.М. Зайцева. - М.: Бином, 2014. - 152 с.: ил.

В снабженном множеством цветных рисунков с четкими обозначениями атласе, созданном специально для оториноларингологов, подробно рассматриваются специфические детали каждого заболевания, что позволяет использовать его и как справочник для врачей других специальностей, помогая последовательно изучать патофизиологию и хирургическую технику при различных нарушениях, возникающих в среднем ухе.

Авторы - хирурги с многолетним стажем - подчеркивают, что все описанные в атласе виды вмешательств и достаточно распространенные, и инновациионые, выполняются ими в клинической практике постоянно. Поэтому все технические аспекты и клинические рекомендации по выполнению вмешательств, наряду с подробным описанием возможных осложнений и их особенностями купирования, позволяют читателю овладеть техникой манипуляций на органе слуха.

11. Джинджихадзе, Р.С. Декомпрессивная краниэктомия при внутричерепной гипертензии / 
Р.С. Джинджихадзе, О.Н. Древаль, В.А. Лазарев. М.: ГЭОТАР-Медиа, 2014. - 112 с. - 6 ил. - (Сер.: Библиотека врача-специалиста. Нейрохирургия).

Сотрудники кафедры нейрохирургии РМАНПО, обобщив собственный многолетний опыт, представили на обсуждение коллег свое представление о показаниях, технике проведения и противопоказаниях к различным видам трепанаций черепа.

Нейрохирургам, работающим в стационарах скорой помощи, наиболее интересным будет знакомство с 8-й главой, в которой на конкретных клинических примерах представлены различные аспекты хирургической техники, этапы выполнения краниэктомии в зависимости от вида патологии, локализации и распространенности внутричерепного процесса. Отдельная глава посвящена анализу возникновения осложнений после проведения вмешательств и их купированию.

12. Ранние клинические формы сосудистых заболеваний головного мозга: руководство для врачей / под ред. Л.С. Манвелова, А.С. Кадыкова. М.: ГЭОТАР-Медиа, 2014. - 344 с.

Ученые научного центра неврологии создали состоящее из трех разделов руководство, подробно излагающее не только основные причины и факторы риска развития сосудистых заболеваний, но и их клиническую симптоматику и основные методы диагностики.

Врачу, ежедневно оказывающемунеотложную помощь при различных состояниях и травмах, постоянно приходится проводить детальное исследование функций головного мозга независимо от наличия или отсутствия жалоб пострадавшего, поэтому второй и третий разделы данного издания будут для него особенно актуальны. Несмотря на отсутствие иллюстраций, компактное изложение материала, хороший справочный аппарат, которым снабжено руководство; большое количество приложений, в которых приведены современные классификации, критерии стратификации рисков и многое другое, позволяет использовать его в нестандартных ситуациях в качестве настольной книги.

13. Травмы глаза / под ред. Р.А. Гундоровой, В.В. Нероева, В.В. Кашникова. - 2-е изд., перераб. и доп. - М.: ГЭОТАР-Медиа, 2014. - 553 с.: ил.

В основе книги, состоящей их четырех частей, лежит новая авторская версия монографии профессора Р.А. Гундоровой, впервые опубликованной свыше 20 лет назад. В первой части подробно излагаются особенности повреждений глазницы и вспомогательного аппарата органа зрения, в том числе проникающих ранений, $и$ общие принципы их лечения. Представленные варианты реконструктивных и органосохраняющих операций при травмах глаза и их последствиях дают возможность врачу первичного звена выбрать адекватную тактику в каждом конкретном случае, в том числе и при черепномозговых повреждениях.

Вторая часть подробно рассматривает все возможные осложнения раневого процесса и тактику проведения профилактических и лечебных мероприятий. Третья часть посвящена контузиям органа зрения; в четвертой части рассматриваются показания к энуклеации глаза и особенности глазного протезирования, в том числе эндопротезирования глазного яблока.

ТРАВМАТОЛОГИЯ И ОРТОПЕДИЯ:

14. Диагностика и лечение переломов лодыжек: учеб.-метод. пособие / сост.: И.Ю. Клюквин [и др.]. - М.: НИИ СП им. Н.В. Склифосовского, 2014. - 50 c.

Представлены современные способы, научно обоснованные методики диагностики, консервативного $u$ оперативного лечения переломов лодыжек, остающихся актуальной задачей для современной травматологии ввиду продолжающегося роста частоты возникновения, большого количества осложнений и, как следствие, не всегда благоприятных исходов лечения.

Многолетний опыт ученых НИИ скорой помощи им. Н.В. Склифосовского, учет анатомо-биомеханических особенностей голеностопного сустава и вариантов его повреждений лег в основу рациональной тактики диагностики и лечения таких пострадавших, позволяющую достигать хороших или отличных непосредственных $u$, что самое главное, - отдаленных результатов.

\section{ДИАГНОСТИКА:}

15. Кармазановский, Г.Г. Эффективное применение рентгеноконтрастных средств в урологии и нефрологии / Г.Г. Кармазановский. - М.: Видар-М, 2014. - 95 с.: ил.

Монография, проиллюстрированная большим количеством фотографий, рассматривает все аспекты использования контрастных средств при проведении мультиспиральной компьютерной томографии (МСКТ) при различных патологических процессах мочеполовой системы у взрослых. Описаны особенности применения метода для каждого состояния, с детальной демонстрацией важности использования контрастного усиления для получения максимально полной информации о патологических изменениях почек и мочевых путей.

Изображения различных фаз контрастного усиления, наряду с подробным описанием неотложных состояний и особенностей применения рентгеноконтрастных веществ, используемых при проведении экстренных МСКТ-исследований, и схем учета радиационной нагрузки на пациента, принимая во внимание их общесоматический статус, делают книгу полезной даже для опытных диагностов.

16. Корн, Д. Рентгенография грудной клетки / Д. Корн, К. Поинтон; пер. с англ. И.П. Королюка. М.: БИНОМ, 2014. - 176 с.: ил.

В 2010 году в Великобритании было опубликовано обширное руководство по лучевой диагностике, подготовленное ведущими специалистами из Великобритании и США, глава из которого издана на русском языке отдельной книгой.

Авторами сделан акцент не только на рентгеноло20в, но и на врачей других специальностей, и исходя из этого, давая подробные интерпретации рентгенограмм грудной клетки при наиболее часто встречающихся и клинически значимых патологических состояниях, в том числе неотложных, они представляют расширенные трактовки и диагностические алгоритмы изучения снимков, снабжая пояснения большим количеством иллюстративного материала.

17. Лемешко, 3.А. Ультразвуковая диагностика заболеваний желудка / 3.А. Лемешко, 3.М. Османова. - М.: ГЭОТАР-Медиа, 2014. - 80 с.: ил. - (Сер.: Актуальные вопросы медицины).

На основании данных литературы и результатов собственного клинического опыта авторов - специалистов из ММА им. И.М. Сеченова и медицинского центра «ОН Клиник» на современном уровне изложе- 
ны принципы и методики ультразвуковой диагностики разнообразной патологии желудка с подробной лучевой семиотикой. Подробно проанализированы возможности УЗИ при аномалиях и пороках развития, воспалительных, эрозивно-язвенных, обструктивных и хронических заболеваниях.

\section{ГИНЕКОЛОГИЯ:}

18. Дамиров, М.М. Лейомиома матки: диагностика и лечение в экстренной гинекологии / М.М. Дамиров. - М.: БИНОМ, 2016. - 248 с.

Монография, написанная заведующим отделением острых гинекологических заболеваний НИИ скорой помощи им. Н.В. Склифосовского, на протяжении всей истории своего существования всегда оказывавшего помощь женщинам, находящимся в ургентных состояниях различной этиологии, посвящена проблеме лечения пациенток с маточными кровотечениями, вызванными лейомиомой матки.

Книга последовательно и подробно излагает основные принципы консервативного и хирургического лечения данной патологии, с особым вниманием к применению мини-инвазивных, органосохраняющих методов лечения, таких как эмболизация маточных артерий при осложненных маточных кровотечениях. Однако, как подчеркивается автором, данные методики не всегда возможно использовать при оказании экстренной медицинской помощи, особенно у необследованных пациенток.

С современных позиций рассмотрены вопросы терминологии, классификации, этиологии и патогенеза лейомиомы матки, в том числе роли апоптоза, в развитии этого заболевания, а также его клинико-инструментальной и морфологической диагностики.

Коллектив научной медицинской библиотеки видит своей основной задачей информирование читателей журнала о современных взглядах как можно более широкого круга отечественных и зарубежных специалистов, отраженных в научных публикациях.

Предпочтение же анализу печатных изданий не является данью прошлому, но отражает общеизвес-

\section{ПСИХИАТРИЯ:}

19. Антропов, Ю.А. Диагностика психических болезней (избранные лекции: шизофрения, паранойя, психоз истощения и др.) / Ю.А. Антропов. М.: ГЭОТАР-Медиа, 2014. - 264 с. - (Сер.: Б-ка врача-специалиста. Психиатрия).

Новое издание одного из видных представителей Петербуржской психиатрической школы расширено и дополнено главами, в которых с современных позиций рассматриваются целостная нозологическая модель шизофрении и разделы, посвященные психозам различной этиологии. Многолетний опыт врача-клинициста и педагога воплотился в лекциях, которые были прочитаны автором в последние годы на циклах повышения квалификации психиатров. Особенно интересными для врачей, работающих в стационарах неотложной помощи, будут главы, касающиеся дифференциальной диагностики инфекционных психозов, психозов истощения и других эндогенных бредовых состояний.

Подчеркнута роль первичного обследования больного, начинающегося с изучения его внешнего вида, особенностей контакта, выявления жалоб, изучения анамнеза настоящего заболевания, семейного анамнеза, биографии больного и многого другого, необходимого для постановки правильного диагноза. Автор категорически возражает против превращения современной психиатрии из области «искусства врачевания» в сферу медицинских услуг, для которой характерен комплекс упрощенных приемов.

тный в литературе факт, подтвержденный многочисленными многоцентровыми исследованиями по психологии чтения, более полноценного восприятия информации с традиционных носителей по сравнению с электронными документами.

Подготовлено

Лукьяновой Евгенией Евгеньевной, кандидатом педагогических наук, заведующей научномедицинской библиотекой НИИ СП им. Н.В. Склифосовского Департамента здравоохранения г. Москвы e-mail: evgevgluk@yandex.ru 